\title{
Risk analysis methods of the water resources system under uncertainty
}

\author{
Zeying GUI, Chenglong ZHANG, Mo LI, Ping GUO (ه)
}

Centre for Agricultural Water Research in China, China Agricultural University, Beijing 100083, China

\begin{abstract}
The main characteristic of the water resources system (WRS) is its great complexity and uncertainty, which makes it highly desirable to carry out a risk analysis of the WRS. The natural environmental, social economic conditions as well as limitations of human cognitive ability are possible sources of the uncertainties that need to be taken into account in the risk analysis process. In this paper the inherent stochastic uncertainty and cognitive subjective uncertainty of the WRS are discussed first, from both objective and subjective perspectives. Then the quantitative characterization methods of risk analysis are introduced, including three criteria (reliability, resiliency and vulnerability) and five basic optimization models (the expected risk value model, conditional value at risk model, chance-constrained risk model, minimizing probability of risk events model, and the multi-objective optimization model). Finally, this paper focuses on the various methods of risk analysis under uncertainty, which are summarized as random, fuzzy and mixed methods. A more comprehensive risk analysis methodology for the WRS is proposed based on the comparison of the advantages, disadvantages and applicable conditions of these three methods. This paper provides a decision support of risk analysis for researchers, policy makers and stakeholders of the WRS.
\end{abstract}

Keywords water resources system, evaluation criterion, optimization model, risk analysis method, uncertainty

\section{Introduction}

The water resources system (WRS) is the sum total of available water from a variety of sources that can be used by humans within a certain region ${ }^{[1]}$. It comprises many

Received June 9, 2015; accepted October 14, 2015

Correspondence: guop@cau.edu.cn interactive parts with multi-water resources, multi-regions and multi-users, such as rivers, streams, lakes, groundwater regimes, reservoirs, dams and bifurcations, as well as cities, towns, and water users. At the same time, climate change and human activity could affect the systems at a regional scale and lead to more significant spatial and temporal variations of water resources in the basin and thus the associated environmental and ecological conditions. Therefore, available water supply is one of the crucial issues that have been seriously restricting the global social and economic development and is likely to continue to do so in the future. This will lead to increasingly severe water scarcity $^{[2]}$ and increased frequency of incidents of water pollution, drought and flood ${ }^{[3]}$. These problems increase the WRS higher complexity and uncertainty ${ }^{[4]}$. Therefore, humans need to confront the ensuing droughts, floods, water pollution, while they exploit and utilize water resources. Such adverse events inevitably lead to risks, such as economic loss and ecological damage. Naturally the following series of questions are elicited ${ }^{[5,6]}$ : What are the risks? What are the source of these risks? What adverse events mentioned above will lead to failure? How likely is this? How severe is it? To solve the above questions, the implications of risk should be first understood.

Risk is the opposite of reliability, that is, the risk can be expressed as one minus the reliability. Risk is always intertwined with uncertainties and hazards ${ }^{[7]}$. Risk can be defined as stochastic characteristics of potential output, while uncertainty is derived from the relative lack of knowledge ${ }^{[8]}$. A distinction between risk, uncertainty and hazard was made by Kaplan and Garrick in $1981^{[6]}$. Hazard emphasizes the sources of risk while risk often refers to the cause of hazardous things, which is a comprehensive embodiment of uncertainty and loss ${ }^{[9]}$. Risk can be minimized, but it cannot be eliminated. When risk is introduced to the WRS, the objects of risk are the undesirable events (i.e., adverse events) under certain temporal-spatial circumstances, and the extent of the risk is measured mainly by the probability of risk and the

(C) The Author(s) 2015. This article is published with open access at http://engineering.cae.cn 
corresponding loss ${ }^{[10]}$. In the WRS, risk is caused by dynamic features of uncertainty. Thus, evaluating uncertainty is essential for the qualitative description or quantitative expression of risk.

There are always uncertainties in the WRS. What are the uncertainties? What are the sources of these? Much research has attempted to answer these questions. For example, there are two major sources of uncertainty in the WRS: randomness and lack of knowledge ${ }^{[11]}$. The sources of uncertainty in the WRS can be summarized into three aspects $^{[12]}$ : natural environmental uncertainty (e.g., precipitation, stream flow, water demand and climate change); social economic uncertainty (e.g., population changes, economic development, policy variations and sudden war); and limitations of human cognitive ability (e.g., uncertainties in the model objectives, constraints and parameters/ variables). Therefore, it is difficult to grasp all information of the WRS. Generally, the problem can be simplified appropriately by identifying the key factors that generate risk.

Based on risk identification, expressions of uncertainty can be explored. There is uncertainty in the system because of inherent randomness or imprecision in the modeling of physical phenomena ${ }^{[13]}$. Hence, the uncertainty has been divided into the inherent variability and error estimates in the risk analysis ${ }^{[14]}$. However, from the objective and subjective perspectives, the uncertainty can be divided into stochastic uncertainty and subjective uncertainty in the process of risk analysis ${ }^{[15]}$. Stochastic uncertainty indicates the inherent characteristics of the system itself, and can be expressed in different ways. Subjective uncertainty indicates people's cognitive ability to further describe the characteristics of the system. The subjectivity emphasizes the cognitive behavior when considering the system. In many cases, it is hard to collect completely objective information about the WRS, because this is restricted by the system and human consciousness and so on. Therefore, when there is a lack of data, or only availability of imprecise data, researchers can estimate the overall situation based on limited sample sizes (either measured or simulated) and further evaluate the risk in the $\mathrm{WRS}^{[16]}$.

In the past decades, a broad spectrum of literature has been published for risk analysis and risk evaluation of the WRS, considering water shortage ${ }^{[4,17,18]}$, reservoir operational management ${ }^{[19,20]}$, water pollution management $^{[21-24]}$ as well as floods ${ }^{[25-29]}$. Some of the basic variables frequently fluctuate with seasonal variation in the WRS, such as stream flow and concentration of pollutants. In addition to analyzing a large amount of data by statistical methods, simulation and prediction of random events can also be performed ${ }^{[30,31]}$. The initial stochastic analysis methods merely focused on digital features like mean and variance, but they were incapable of predicting the likelihood and severity of system failure. System failure can be described by three criteria: reliability, resiliency and vulnerability. These criteria are used to evaluate system performance of a water reservoir ${ }^{[4]}$. If the available data collected are inadequate, other insurmountable problems arise, and the applicability of the stochastic methods will be significantly diminished. Therefore, three fuzzy reliability measures have been developed, including reliability-vulnerability index, robustness index and resiliency index. These indices are capable of handling complicated fuzzy sets and system conditions, and it is an effective way to solve problems for which stochastic methods are inapplicable ${ }^{[32]}$. However, a given fuzzy set implies the need for membership function of the specific expression. Such fuzzy methods that greatly depend on human subjectivity will be brought into question even when expert opinion has been used. Also, the study issues are complex, for example, the characteristics of multivariables in the risk evaluation model are diverse, and some of these have strong randomness, while others have strong fuzziness. Using only one method (a stochastic method or a fuzzy method) will simplify the problem by ignoring the features of the secondary variables, which will naturally affect the reliability and accuracy of the results. Accordingly, a mixed method combining stochastic methods with fuzzy methods has been developed. For instance, the Monte Carlo stochastic simulation method can be used to help generating fuzzy numbers, and obtain more abundant results and the probability of risk ${ }^{[33]}$. Based on stochastic simulation to estimate the inherent random uncertainty of parameters, human-induced uncertainty by fuzzy analysis is presented. The risk assessment results will be more abundant because of the combination of objective with subjective uncertainties ${ }^{[26]}$. However, the majority of the literature describes risk evaluation models for specific or particular problems. Methods to fully quantify the probability and loss for the risk in the WRS have rarely been reported.

Therefore, considering the relationship between risk and uncertainty (Fig. 1), this paper first introduces the commonly used risk analysis evaluation indices and optimization models and, based on this, the existing methods of risk analysis of the WRS are summarized as stochastic, fuzzy and mixed methods. Then, the applicable conditions of various mathematical analysis methods from quantitative perspective are analyzed in depth. Through comparing the advantages and disadvantages of these three methods, this study provides decision support of risk analysis for the researchers, policy makers and other stockholders by formulating a more comprehensive risk analysis methodology for the WRS.

\section{Risk evaluation indices and optimization models}

Identification of risk should be considered first when analyzing the risk in the WRS under uncertainty. That is, all possible sources of uncertainty resulting in system 


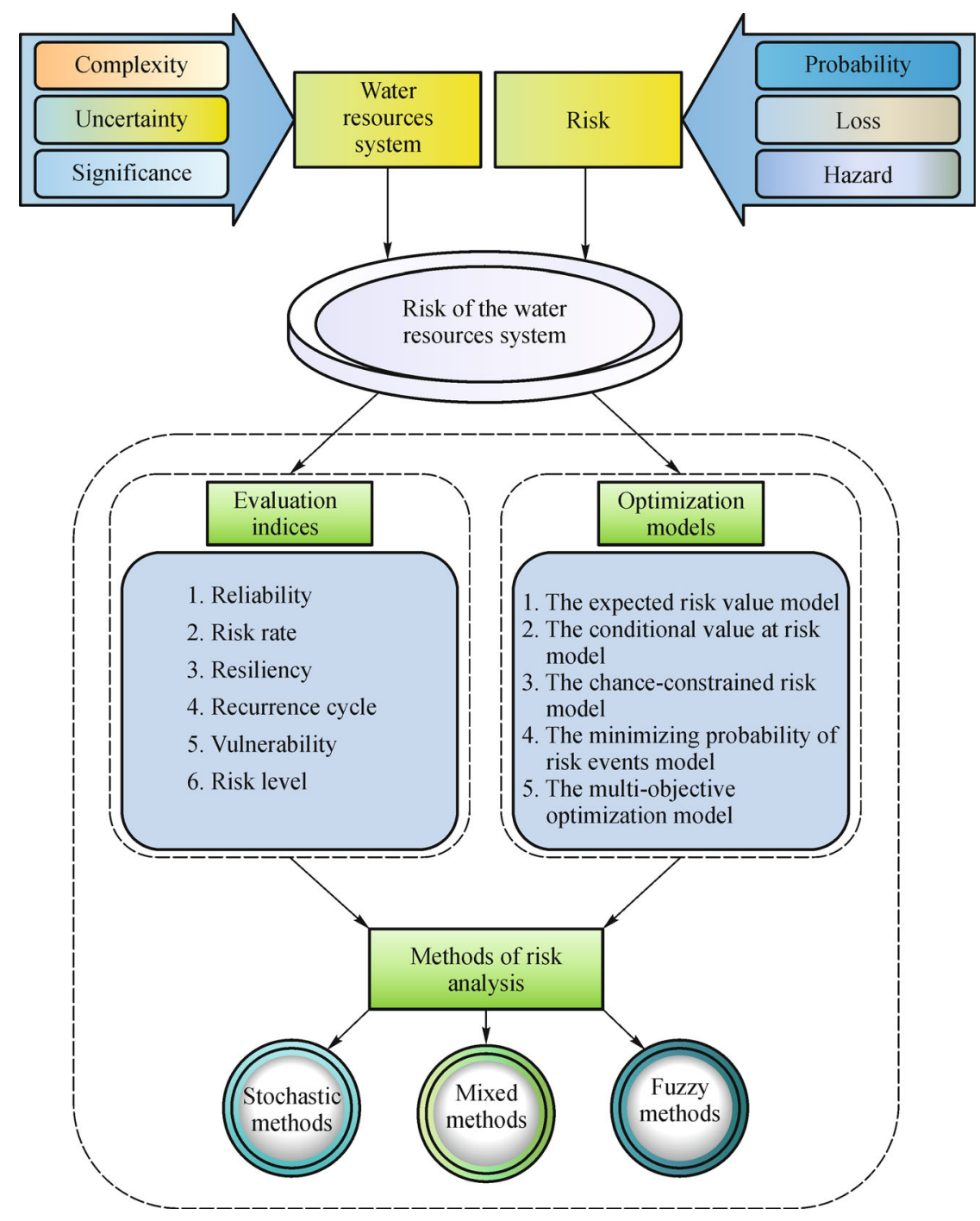

Fig. 1 The framework of water resources system (WRS) risk analysis

failures should be clearly shown. Taking water shortages as an example to identify risk, Fig. 2 shows the conceptual model for identifying the risk factors underlying the risk of water shortages $^{[34]}$.

Figure 2 illustrates the complexity of risk analysis in the WRS. The procedure can be detailed as sources of risk, risk factors, key risk factors and risk consequences. If the loss is selected to indicate the final risk in the WRS, the relationship between the loss and corresponding frequency will be established. The key factors that affect the loss from water shortages are the reduced availability of water and the increased price of that water. Meanwhile, according to comprehensive analysis of all the risk factors, the key factors can be determined. The sources of risk should be listed, including hydrological, hydraulic, structural and supply-demand factors, prior to identifying the risk factors.

The second step is to quantify the risk and there are various risk evaluation indices and optimization models which can be used to measure the effects of the uncertainty $^{[32]}$. Decision makers can choose the evaluation indices and optimization models, individually to evaluate system performances, or the evaluation indices can be used as objective functions or constraints in the optimization models framework.

\subsection{Risk evaluation indices}

Many indices can be used to depict the performance of the WRS. Among them, the mean and the variance are frequently used. In general, the mean and the variance describe the system average level and average deviation from the mean of the parameters, respectively, but they can hardly provide sufficient system information about extremes and probability distribution when the risk failure will occur ${ }^{[4]}$.

Three criteria of risk evaluation can be considered for evaluating the possible performance of the WRS as shown in Table $1^{[4,10,35-37]}$. 


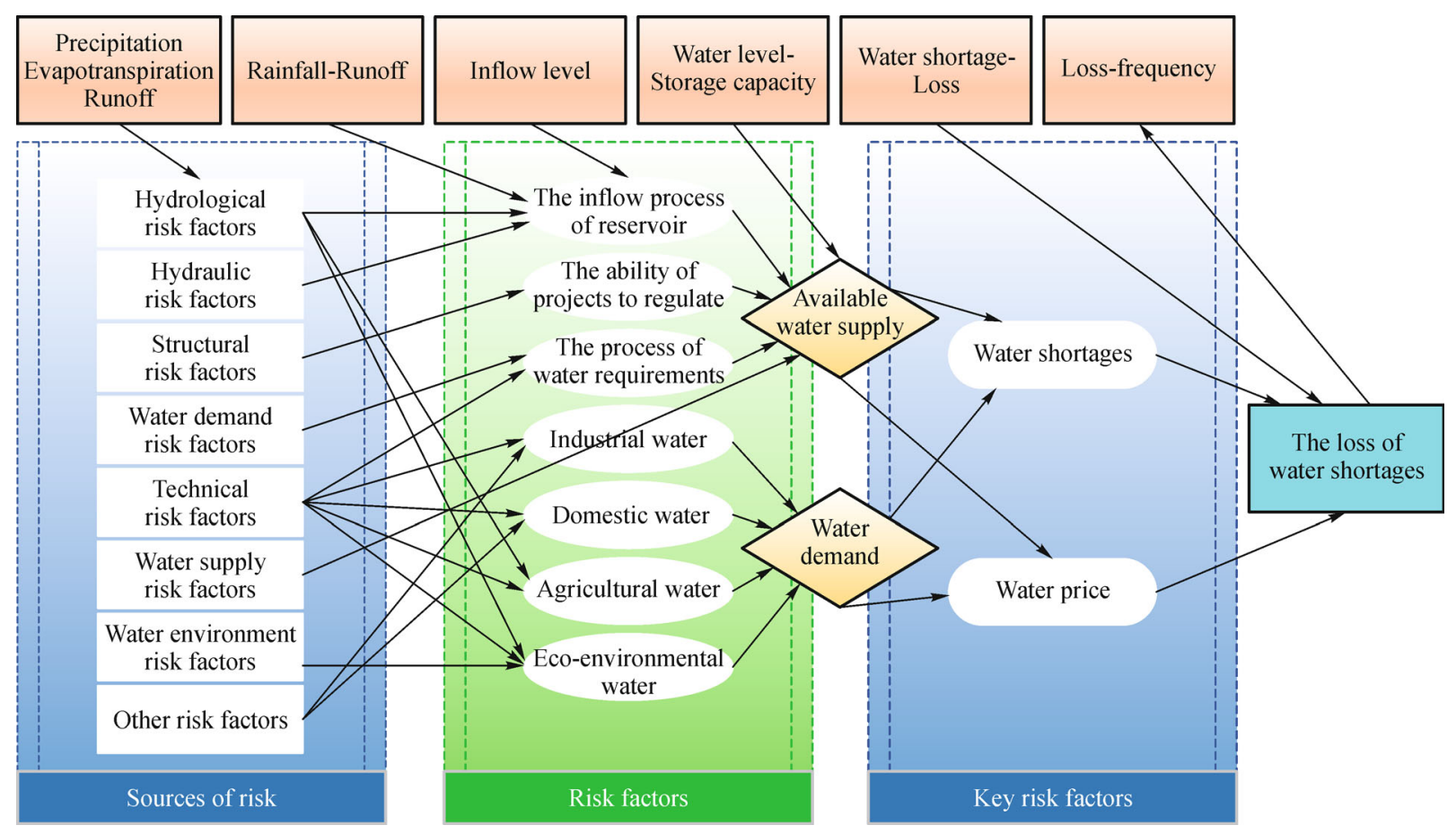

Fig. 2 Conceptual model for identifying the risk factors in the risk of water shortages

Using three aspects (i.e., uncertainty, sensitivity and severity), the risk evaluation indices can be divided into three criteria (reliability, resiliency and vulnerability). With different mathematical expressions for the same criterion, they can be further subdivided into six sub-criteria (reliability, risk rate, resiliency, recurrence cycle, vulnerability and risk level). Taking the reliability as an example, both reliability and risk rate indicate the concept of probability that the WRS is in the normal or an unsatisfactory state, respectively, which satisfies the mathematical equation of $\alpha+r=1$. If $\alpha=1(r=0)$, then the system is in the normal state and has high stability. On the contrary, if $\alpha=0(r=1)$, then the system is in an unsatisfactory state. In most cases, the values of $\alpha(r)$ are typically between 1 and 0 .

Reliability and risk rate are opposites with different focuses on the running state of the WRS. Reliability holds the concept of trust while the risk holds the concept of doubt. However, both reliability and risk rate can only indicate the possibility of system security or failure, without reflecting the nature of risk events inadequately. For example, neither reliability nor risk rate can describe how severe or likely the consequences of a failure may be. Hence, it is necessary to introduce other criteria to describe it. When a failure inevitably occurs in the WRS, indices like resiliency and recurrence cycle can be adopted to measure how quickly the system returns to a running state. Furthermore, means to describe the results of a failure and their severity, the vulnerability and risk level are introduced into evaluation indices ${ }^{[10,36]}$.
In practical applications, a single evaluation index provides insufficient information when the possible sources of uncertainty are complex. Therefore, a single index cannot accurately measure and evaluate the risk (system performance). Appropriate combinations can be chosen to carry on the comprehensive evaluation, fully reflecting the risk of the WRS. Additionally, risk evaluation indices can also be regarded as inputs of the optimization model, using the results of optimization models to reflect their advantages and disadvantages. Thus, several risk analysis models are derived.

\subsection{Optimization models}

Based on the uncertainty theory, there are five ways to formulate a risk analysis model.

(1) For the risk variables or risk losses in the water resource allocation problems, the expected risk value model was introduced ${ }^{[38-42]}$. The objective function can be formulated as minimizing the expected value of risk losses, and the constraints can also be expressed by the expected value.

(2) Safeguarding measures should be taken to reduce the risk in the WRS. In most cases, it is essential for minimizing the expected maximum possibility of risk losses, or minimizing the average value that exceeds a certain risk loss threshold under a certain level of confidence. The conditional value at risk model can be formulated in response to the above issues ${ }^{[43-45]}$.

(3) If it is allowed to violate the constraints under a 


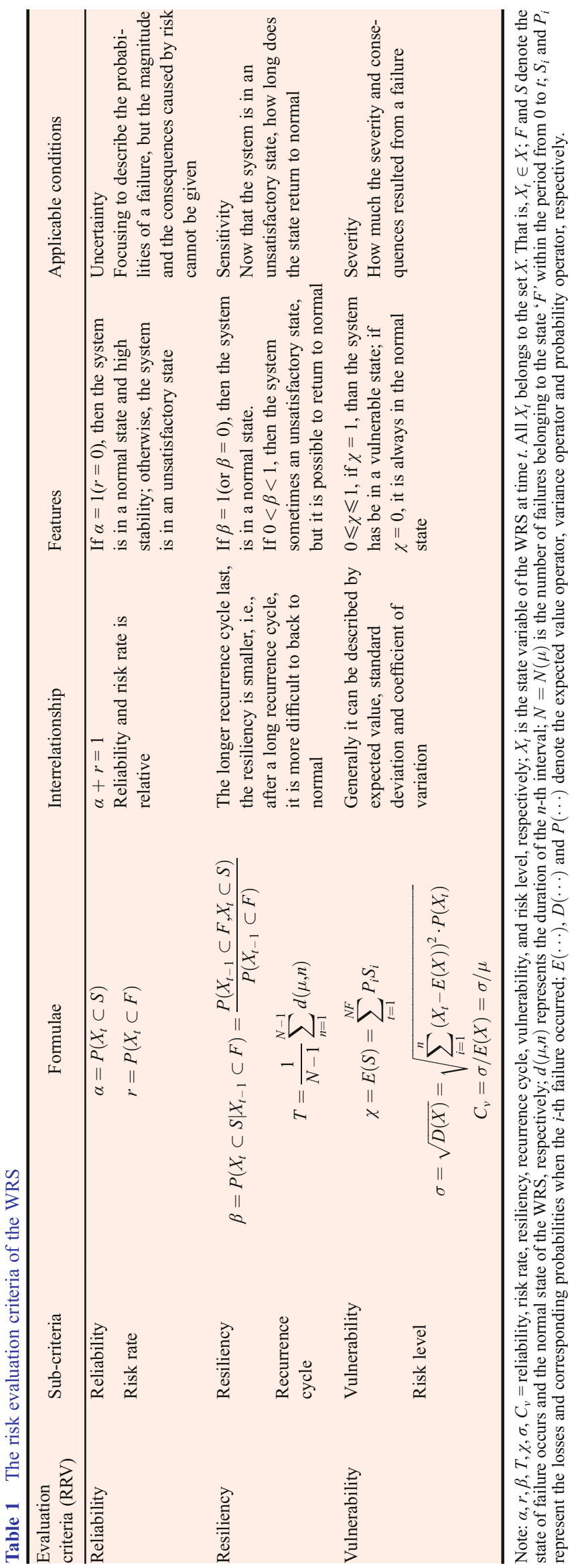


certain level of confidence $\alpha(\alpha \in[0,1])$, the probability for constraints should be less than or equal to1- $\alpha$. Then, the chance-constrained risk model minimizing value at risk chance can be formulated ${ }^{[46-49]}$.

(4) Decision makers hope that the probability of risk events should be as small as possible, i.e., minimizing the probability of risk events under uncertainty constraints. For this reason, the minimizing probability of risk event model has been developed.

(5) From the perspective of the sustainable use of resources, pursuing the maximum comprehensive benefits, including economic, social and environmental, are more desirable than simply pursuing economic benefit. In such cases, it is necessary to formulate a multi-objective optimization model based on uncertainty systems ${ }^{[50,51]}$. For each single objective, according to the actual situation, decision makers can choose any model or any combination of the four basic models as listed in Table $2^{[51,52]}$.

Based on the above risk evaluation indices and optimization models, risk analysis methods should be considered after quantifying the risk events.

\section{Risk analysis/assessment methods of the WRS}

The main risk analysis/assessment methods of the WRS include subjective probability method (Delphi method) ${ }^{[8]}$, parameter analysis, extreme value statistics ${ }^{[53,54]}$, uncertainty method, support vector machine ${ }^{[55]}$, and maximum entropy risk analysis method ${ }^{[56]}$. Each method has its own advantages and disadvantages, which should also be analyzed specifically. If the risk evaluation indices are random or fuzzy, uncertainty methods are adopted to solve the problems.

Generally, decision makers can quantify the risk by two major variables coinciding with the characteristics of the information available and the data collected. Taking the reliability as an example, (1) when the collected data or samples are sufficient, it can be assumed that the stochastic uncertainties obey a certain probability distribution (e.g., normal distribution, exponential distribution, Poisson distribution, gamma distribution or Pearson type- III distribution), then the risk can be quantified by using probability and statistics methods, and (2) when the samples are insufficient to support the stochastic probability distributions, fuzzy sets theory can be adopted as an effective research tool to assess reliability using the concept of fuzzy probability.

This paper focuses on the randomness and fuzziness characteristics of risk analysis in the WRS. The stochastic methods are applied to the evaluation indices and optimization models with stochastic characteristics, while the fuzzy methods are used for the evaluation indices and optimization models with fuzzy performance. The applications of the stochastic and fuzzy methods as well as mixed methods are discussed below.

\subsection{Stochastic methods}

The significant characteristic of a stochastic method is to reflect the probability of risk events, quantifying them as the probability distribution or cumulative probability function, which can be obtained by empirical estimation or theoretical simulation. The uncertainty variables can be defined as certain common and typical probability distributions, but it is a great challenge to integrate the probability density function directly. It is difficult to estimate and determine the distribution parameters accurately and less likely to focus on the interrelationship among variables. However, the Monte Carlo stochastic simulation is a common method to solve this problem. Especially, with the rapid development of computer science, it is easy to simulate the actual situation and to reveal the principles of the system by generating a large number of random numbers.

For example, the Monte Carlo stochastic simulation method has been used to generate 10000 sets of risk factors to solve the multi-objective risk analysis model of water resources optimization allocation, and the fundamental target of sustainable utilization of water resources was realized $^{[57,58]}$. The Bayesian principle ${ }^{[59,60]}$, the maximum

Table 2 The risk optimization models of the WRS

\begin{tabular}{|c|c|c|c|}
\hline Optimization models & Objective functions & Constraints & References \\
\hline The expected risk value model & $\min E[f(\boldsymbol{x} ; \boldsymbol{\xi})]$ & $E\left[g_{j}(\boldsymbol{x} ; \boldsymbol{\xi})\right] \leqslant 0$ & {$[38-42]$} \\
\hline The conditional value at risk model & $\min \phi_{\alpha}(\boldsymbol{x} ; \boldsymbol{\xi})$ & $g_{j}(\boldsymbol{x} ; \boldsymbol{\xi}) \leqslant 0$ & [43-45] \\
\hline The chance-constrained risk model & $\min f(\boldsymbol{x} ; \boldsymbol{\xi})$ & $\left\{\begin{array}{l}\operatorname{Pr}\{f(\boldsymbol{x} ; \boldsymbol{\xi}) \leqslant f\} \geqslant \alpha \\
\operatorname{Pr}\left\{g_{j}(\boldsymbol{x} ; \boldsymbol{\xi}) \leqslant f\right\} \geqslant \beta\end{array}\right.$ & {$[46-49]$} \\
\hline The minimizing probability of risk event model & $\min \operatorname{Pr}\left\{h_{k}(\boldsymbol{x} ; \boldsymbol{\xi})\right\}$ & $g_{j}(\boldsymbol{x} ; \boldsymbol{\xi}) \leqslant 0$ & - \\
\hline The multi-objective optimization model & $\min \left[f_{1}(\boldsymbol{x} ; \boldsymbol{\xi}), f_{2}(\boldsymbol{x} ; \boldsymbol{\xi}), \ldots, f_{m}(\boldsymbol{x} ; \boldsymbol{\xi})\right]$ & $g_{j}(\boldsymbol{x} ; \boldsymbol{\xi}) \leqslant 0$ & {$[50-52]$} \\
\hline
\end{tabular}

Note: $E[\cdots]$ denotes the expected value operator; the vector $\boldsymbol{x}$ represents the decision variables; the vector $\boldsymbol{\xi}$ is composed by the uncertain risk variables; $f(\boldsymbol{x} ; \boldsymbol{\xi})$ indicates the objective function of the system losses risk; $g_{j}(\boldsymbol{x} ; \boldsymbol{\xi})$ expresses the constrained function of risk, $j=1,2, \ldots, p$ represents the number of constraints; $\phi_{\alpha}(\boldsymbol{x} ; \boldsymbol{\xi})$ is the loss value of $\alpha-\mathrm{CVaR}$ (conditional value at risk) under confidence level $\alpha ; \alpha$ and $\beta$ are predefined confidence levels, representing the violation probabilities of the objective functions and the constraints, respectively; $\operatorname{Pr}\{\cdots\}$ denotes the probability of risk event $\{\cdots\}$ under uncertainty; $k=1,2, \ldots, q$ represents the number of risk events $h_{k}(\boldsymbol{x} ; \xi) \leqslant 0$ 
entropy principle ${ }^{[61-63]}$ and Markov chain ${ }^{[64,65]}$ can also be introduced into the study framework to solve the stochastic features of risk analysis in the WRS. The Bayesian method has been used to analyze atmosphere-ocean global circulation models under uncertainty, and further analyze the water demand-consumption risk by Monte Carlo stochastic simulation ${ }^{[59]}$. Since by using the Bayesian method it is difficult to get a post-distribution, the Markov chain Monte Carlo method has obvious continuity advantages in describing the rainfall-runoff relationship $^{[65]}$.

Although the principle of the Monte Carlo method is simple, the simulation results depend on the sample size and number, and the hypothesis of the basic variables is pretty sensitive. Moreover, the calculation workload is heavy and time-consuming. Therefore, another advanced and convenient method can be chosen for indirect estimation to improve the computational efficiency of the traditional Monte Carlo simulation, such as advanced first order second moment ${ }^{[66,67]}$, stratified sampling ${ }^{[68]}$, Latin hypercube sampling ${ }^{[69]}$ or an artificial neural network ${ }^{[70]}$.

\subsection{Fuzzy methods}

Risk is relative, without clear attribute, definition or obvious boundaries (e.g., difficult to use deterministic value), which is a typical conception of fuzzy sets. The problem can be described by fuzzy theory, especially when the probability distribution is unknown and the sample size is pretty small.

On the one hand, according to fuzzy mathematics, risk evaluation indices can be divided into several levels, and thus a comprehensive risk evaluation of the WRS is performed. Compared with the single risk index, mentioned above, sub-criteria (Table 2) can determine the risk of the WRS more completely, so as to provide decisionmaking support for water resources planning and management. The risk level of the evaluation indices can be classified as very-low, low, medium, high and very-high. If the weight of each index is determined by an analytic hierarchy process, the subjective factor of the human may cause deviation of the evaluation results ${ }^{[9]}$. Furthermore, the researchers could use support vector machine ${ }^{[55]}$ and entropy theory ${ }^{[56]}$ to determine weights on the basis of mathematical theory. By incorporating objective weights with subjective weights, the comprehensive weights can be determined. The results generated by this approach are objective, more reasonable and reliable.

When triangular fuzzy numbers ${ }^{[71]}$ and generalized trapezoidal fuzzy numbers ${ }^{[72]}$ are taken as the study objects, both of them measure the similarities of fuzzy sets for fuzzy risk analysis. When multiple subcomponents in the fuzzy risk system are expressed as fuzzy linguistic terms (e.g., each risk level corresponding to a fuzzy number), the total risk fuzzy numbers are obtained by the operation of fuzzy arithmetic. Finally, the similarity between total risk fuzzy numbers and each subcomponent is measured, and the total risk level is obtained.

On the other hand, certain fuzzy variables can be considered as the inputs to an optimization model, and the similar symbols ( $\geqslant$ and $\leqslant$ ) appeared in the constraints, which are used to express the fuzzy relationship ${ }^{[73]}$. For example, the interval membership function could be employed to describe the discreteness of different scenarios of inflows and the ambiguity of upper and lower boundaries ${ }^{[74]}$. By incorporating fuzzy numbers with the chance constrained programming, the capacity expansion problems coping with floods can be described ${ }^{[47]}$.

In general, fuzzy sets theory can be applied widely. It is possible to provide an alternative in the case where a random distribution of variable is difficult to obtain. Compared with the stochastic methods, fuzzy methods have relatively prominent subjectivity, which can sometimes be considered as a major flaw.

\subsection{Mixed methods}

Based on the original single uncertainty method, the stochastic, fuzzy (including gray and interval) methods can be combined into a multiple uncertainties framework. In the absence of available statistical data and a proper physical model, fuzzy probability is used to depict and evaluate damages caused by floods, tornadoes, earthquakes and other natural disasters ${ }^{[75]}$. Similarly, the characteristics of stochastic and fuzzy methods could be taken into account, to describe fuzziness and random risk probability distribution of the WRS by the membership function and logistic regression ${ }^{[18]}$. Based on a similar conception, a two-stage integer programming model, infinite two-stage stochastic programming model and interval stochastic fuzzy programming have been proposed for flood management, agricultural water management and water resources carrying capacity risk assessment ${ }^{[76-78]}$.

The predominant advantage of the mixed methods is to accurately reflect the actual characteristics of risk assessment in the WRS. With the support of existing data, the various parameters/variables can be expressed in the form of random variables or discrete interval/fuzzy sets, reflecting multiple uncertainties in the WRS, expressing complex variables inside the system and their relationships. The workload of processing data will increase considerably, however, and the mathematical model used for processing variables and its coupled relationship will be more complicated.

Mathematical analysis methods of risk assessment for the WRS are still developing rapidly, such as robust risk analysis method ${ }^{[79]}$, the chaotic method, genetic algorithm $^{[80,81]}$, wavelet analysis, and the geographic information system.

For practical problems, appropriate analysis methods 
Table 3 Comparison among the three methods of risk analysis in the WRS

\begin{tabular}{|c|c|c|c|c|}
\hline \multirow{2}{*}{ Methods } & \multirow{2}{*}{ Features } & \multirow{2}{*}{ Applicable conditions } & \multicolumn{2}{|c|}{ An overview of the application } \\
\hline & & & Advantages & Disadvantages \\
\hline \multirow[t]{2}{*}{ Stochastic } & $\begin{array}{l}\text { 1. Sensitivity to hypothesis, } \\
\text { depending on sample size } \\
\text { and the number of sample }\end{array}$ & $\begin{array}{l}\text { 1. The number of samples } \\
\text { is relatively sufficient }\end{array}$ & $\begin{array}{l}\text { 1. The description of the } \\
\text { "probability" of risk is } \\
\text { more realistic }\end{array}$ & $\begin{array}{l}\text { 1. The gap between the assumption } \\
\text { and the practice }\end{array}$ \\
\hline & $\begin{array}{l}\text { 2. High precision, sufficient } \\
\text { results }\end{array}$ & $\begin{array}{l}\text { 2. Probability distribution } \\
\text { can be obtained by an } \\
\text { empirical or theoretical } \\
\text { estimation }\end{array}$ & 2. Mature development & $\begin{array}{l}\text { 2. Heavy workload and complex } \\
\text { computation }\end{array}$ \\
\hline \multirow[t]{2}{*}{ Fuzzy } & $\begin{array}{l}\text { Describing the probability } \\
\text { distribution is unknown and } \\
\text { the sample size is pretty small }\end{array}$ & $\begin{array}{l}\text { 1. Data are relatively } \\
\text { insufficient }\end{array}$ & $\begin{array}{l}\text { 1. Subjective evaluation } \\
\text { can be involved }\end{array}$ & $\begin{array}{l}\text { 1. The membership function } \\
\text { construction is inconsistent } \\
\text { standard yet }\end{array}$ \\
\hline & & $\begin{array}{l}\text { 2. Focus on the magnitude } \\
\text { of the risk of relativity }\end{array}$ & $\begin{array}{l}\text { 2. Widely used in the risk } \\
\text { evaluation indices }\end{array}$ & $\begin{array}{l}\text { 2. The principles of selecting } \\
\text { the indices are inconsistent }\end{array}$ \\
\hline Mixed & $\begin{array}{l}\text { Combination of the above } \\
\text { two methods }\end{array}$ & $\begin{array}{l}\text { Describing fuzziness and } \\
\text { risk random probability } \\
\text { distribution }\end{array}$ & $\begin{array}{l}\text { Accurately reflect the actual } \\
\text { characteristics of risk } \\
\text { assessment in the WRS }\end{array}$ & $\begin{array}{l}\text { 1. The workload of processing } \\
\text { data will increase worrisomely } \\
\text { 2. The mathematical model used } \\
\text { for processing variables and its } \\
\text { coupling relationship will be } \\
\text { more complicated }\end{array}$ \\
\hline
\end{tabular}

should be selected based on the specific assessment objectives, available information and data, the study subject and the results of requirements. A brief review of the above three risk analysis methods shows their applicable conditions as well as their advantages and disadvantages (Table 3 ) and this is intended to provide decision support for researchers and policy makers in the WRS.

\section{Conclusions and perspectives}

Research on risk analysis methods in the WRS described in this paper can be summarized into three aspects: the inherent stochastic uncertainty and cognitive subjective uncertainty of the WRS from the objective and subjective perspectives are discussed; three criteria including six subcriteria and five basic optimization models are introduced to quantify the risk; and various methods of risk analysis under uncertainty are summarized including random, fuzzy and mixed methods. By analyzing the conditions for their application, and the advantages and disadvantages of the application of the three mentioned methods, a more comprehensive risk analysis methodology for the WRS is proposed. This paper is intended to provide decision support for researchers, policy makers and stakeholders of the WRS.

However, the risk events have become increasingly complex since the beginning of the 21 st century. Therefore it is argued that improvements in the future can be made in two directions.

(1) Risk evaluation is required to be increasingly complex to cope with the temporal and spatial variation of adverse events. Apart from a warmer global climate, population, economic activity, vegetation cover, land use and rising sea level will be the mainly drivers of change. Reservoir construction, pollution, irrigation and other water utilization will have a strong impact on the security of the WRS. Additionally, transfer of water rights for agriculture and urban and environmental water demand or supply will have a great influence on the risk assessment. This can be further explored from the perspective of a market economy.

(2) Risk analysis methods need to be more sophisticated to cope with the complexity of the WRS. Considering the scope of risk study in the WRS is expanding gradually, more comprehensive evaluation indices, advanced optimization models and uncertainty methods of risk analysis will be further developed. In particular, economic and social implications are often regarded as dominant factors for the existing indices and models, without considering the effect of the ecological environment. Quantification of ecological effects is difficult to achieve, however, with the implementation of regional ecological protection, ecological factors are bound to become a focus for future risk analysis in the WRS. In addition, the risk management issues (e.g., the analysis of feasible choice, balance the costs and risk benefits relationships, and the impact of the final decision) also deserve future discussion.

Acknowledgements This research was supported by the National Natural Science Foundation of China (41271536, 51439006, and 91425302).

Compliance with ethics guidelines Zeying Gui, Chenglong Zhang, Mo Li, and Ping Guo declare that they have no conflict of interest or financial conflicts to disclose.

This article does not contain any studies with human or animal subjects performed by any of the authors. 


\section{References}

1. Li Y P, Huang G H. Risk analysis and management for water resources systems. Stochastic Environmental Research and Risk Assessment, 2013, 27(3): 593-597

2. Wang X Q. A study on regional difference of fresh water resources shortage in China. Journal of Natural Resources. 2001, 16(6): 516, 520 (in Chinese)

3. Loucks D P, Van B E, Stedinger J R, Dijkman J P M, Villars M T. Water resources systems planning and management: an introduction to methods, models and applications. Paris: UNESCO, 2005

4. Hashimoto T, Stedinger J R, Loucks D P. Reliability, resiliency, and vulnerability criteria for water resource system performance evaluation. Water Resources Research, 1982, 18(1): 14-20

5. Haimes Y Y. Total Risk Management. Risk Analysis, 1991, 11(2): 169-171

6. Kaplan S, Garrick B J. On the quantitative definition of risk. Risk Analysis, 1981, 1(01): 11-27

7. Paté-Cornell M E. Uncertainties in risk analysis: six levels of treatment. Reliability Engineering \& System Safety, 1996, 54(2): 95-111

8. U. S. Water Resources Council. Principles and standards for water and related land resources planning. Federal Register, 1980, (September): 28

9. Tartakovsky D M. Assessment and management of risk in subsurface hydrology: a review and perspective. Advances in Water Resources, 2013, 51: 247-260

10. Ruan B Q, Han Y P, Wang H, Jiang R F. Fuzzy comprehensive assessment of water shortage risk. Journal of Hydraulic Engineering, 2005, (08): 906-912 (in Chinese)

11. Simonivic S P. Risk in sustainable water resources management, in Sustainability of Water Resources Under Increasing Uncertainty. Proceedings of the Rabat Symposium. 1997, 240: 3-17

12. Ruan B Q, Liang R J, Chen S J. A method for risk analysis and evaluation of water supply and demand. Journal of Hydraulic Engineering, 2000, (09): 1-7 (in Chinese)

13. Ang A H S, Tang W H. Probability concepts in engineering planning and design. Beijing: Metallurgical Industry Press, 1991, 430-460 (in Chinese)

14. Tang W H, Yucemen M S, Ang A H S. Probability-based short-term design of soil slopes. Canadian Geotechnical Journal, 1976, 13(3): 201-215

15. Helton J C. Treatment of uncertainty in performance assessments for complex systems. Risk Analysis, 1994, 14(4): 483-511

16. Dechant $\mathrm{C}$ M, Moradkhani H. On the assessment of reliability in probabilistic hydro meteorological event forecasting. Water Resources Research, 2015, 51(6): 3867-3883

17. Babel M S, Das G A, Nayak D K. A model for optimal allocation of water to competing demands. Water Resources Management, 2005, 19(6): 693-712

18. Wang H R, Qian L X, Xu X Y, Wang Y. Model for evaluating water shortage risk based on fuzzy probability and its application. Journal of Hydraulic Engineering, 2009, (07): 813-821 (in Chinese)

19. Brekke L D, Maurer E P, Anderson J D, Dettinger M D, Townsley E $\mathrm{S}$, Harrison A, Pruitt T. Assessing reservoir operations risk under climate change. Water Resources Research, 2009, 45(4): W04411

20. Loaiciga H A, Mariño M A. Risk analysis for reservoir operation. Water Resources Research, 1986, 22(4): 483-488

21. Mcbean E A. Risk characterization for arsenic-impacted water sources, including ground-trothing. Stochastic Environmental Research and Risk Assessment, 2013, 27(3): 705-711

22. Ghosh S, Mujumdar P P. Risk minimization in water quality control problems of a river system. Advances in Water Resources, 2006, 29 (3): 458-470

23. Mujumdar P P, Sasikumar K. A fuzzy risk approach for seasonal water quality management of a river system. Water Resources Research. 2002, 38(1): 1-5, 5-9

24. Sasikumar K, Mujumdar P P. Application of fuzzy probability in water quality management of a river system. International Journal of Systems Science, 2000, 31(5): 575-591

25. Ahmad S S, Simonovic S P. Spatial and temporal analysis of urban flood risk assessment. Urban Water Journal, 2013, 10(1): 26-49

26. Yu J J, Qin X S, Larsen O. Joint Monte Carlo and possibilistic simulation for flood damage assessment. Stochastic Environmental Research and Risk Assessment, 2013, 27(3): 725-735

27. Thumerer T, Jones A P, Brown D. A GIS based coastal management system for climate change associated flood risk assessment on the east coast of England. International Journal of Geographical Information Science, 2000, 14(3): 265-281

28. Anselmo V, Galeati G, Palmieri S, Rossi U, Todini E. Flood risk assessment using an integrated hydrological and hydraulic modelling approach: A case study. Journal of Hydrology, 1996, 175(1-4): 533-554

29. Dyck J, Willems P. Probabilistic flood risk assessment over large geographical regions. Water Resources Research, 2013, 49(6): 3330-3344

30. James A L, Oldenburg C M. Linear and Monte Carlo uncertainty analysis for subsurface contaminant transport simulation. Water Resources Research, 1997, 33(11): 2495-2508

31. Whitehead P, Young P. Water quality in river systems: Monte-Carlo analysis. Water Resources Research, 1979, 15(2): 451-459

32. El-Baroudy I, Simonovic S P. Fuzzy criteria for the evaluation of water resource systems performance. Water Resources Research, 2004, 40(10): W10503

33. Wang Z U, Jin J L, Li R Z, Wang M W, Zhou Y L. Risk based regional water security assessment method using stochastic simulation and triangular fuzzy numbers. Journal of Sichuan University, 2010, 42(6): 1-5

34. Han Y P. Study on risk management of water resources shortage. Dissertation for the Doctoral Degree. Xi'an: Xi'an University of Technology, 2003 (in Chinese)

35. Kenji J, Xu Z X, Akika D, Kaname T. Risk assessment of a water supply system during drought. Water Resources Development, 1995 , 11(2): 185-204

36. Moy W S, Cohon J L, Revelle C S. A programming model for analysis of the reliability, resilience, and vulnerability of a water supply reservoir. Water Resources Research, 1986, 22(4): 489-498

37. Kjeldsen T R, Rosbjerg D. Choice of reliability, resilience and vulnerability estimators for risk assessments of water resources systems. Hydrological Sciences Journal, 2004, 49(5): 755-767

38. Guo P, Huang G H, He L, Sun B W. ITSSIP: Interval-parameter 
two-stage stochastic semi-infinite programming for environmental management under uncertainty. Environmental Modelling \& Software, 2008, 23(12): 1422-1437

39. Guo P, Huang G H, Zhu H, Wang X L. A two-stage programming approach for water resources management under randomness and fuzziness. Environmental Modelling \& Software, 2010, 25(12): $1573-1581$

40. Fan Y R, Huang G H, Guo P, Yang A L. Inexact two-stage stochastic partial programming: application to water resources management under uncertainty. Stochastic Environmental Research and Risk Assessment, 2012, 26(2): 281-293

41. Li M, Guo P, Fang S Q, Zhang L D. An inexact fuzzy parameter two-stage stochastic programming model for irrigation water allocation under uncertainty. Stochastic Environmental Research and Risk Assessment, 2013, 27(6): 1441-1452

42. Mark G, Joseph Y S L, Meng F W. A stochastic model for risk management in global supply chain networks. European Journal of Operational Research, 2007, 182(1): 164-173

43. Andersson F, Mausser H, Rosen D, Uryasev S. Credit risk optimization with Conditional Value-at-Risk criterion. Mathematical Programming, 2001, 89(2): 273-291

44. Rockafellar R T, Royset J O, Miranda S I. Superquantile regression with applications to buffered reliability, uncertainty quantification, and conditional value-at-risk. European Journal of Operational Research, 2014, 234(1): 140-154

45. Wang Y Q. Robust v-support vector machine based on worst-case conditional value-at-risk minimization. Optimization Methods \& Software, 2012, 27(6): 1025-1038

46. Guo P, Chen X H, Li M, Li J B. Fuzzy chance-constrained linear fractional programming approach for optimal water allocation. Stochastic Environmental Research and Risk Assessment, 2014, 28 (6): 1601-1612

47. Guo P, Huang G H, Li Y P. An inexact fuzzy-chance-constrained two-stage mixed-integer linear programming approach for flood diversion planning under multiple uncertainties. Advances in Water Resources, 2010, 33(1): 81-91

48. Huang G H. A hybrid inexact-stochastic water management model. European Journal of Operational Research, 1998, 107(1): 137-158

49. Morgan D R, Eheart J W, Valocchi A J. Aquifer remediation design under uncertainty using a new chance constrained programming technique. Water Resources Research, 1993, 29(3): 551-561

50. Li M, Guo P. A multi-objective optimal allocation model for irrigation water resources under multiple uncertainties. Applied Mathematical Modelling, 2014, 38(19-20): 4897-4911

51. Zeng X T, Kang S Z, Li F S, Zhang L, Guo P. Fuzzy multi-objective linear programming applying to crop area planning. Agricultural Water Management, 2010, 98(1): 134-142

52. Guo P, Huang G H. Two-stage fuzzy chance-constrained programming: application to water resources management under dual uncertainties. Stochastic Environmental Research and Risk Assessment, 2009, 23(3): 349-359

53. Fu X, Wang L P, Ji C M. Application of statistics of extremes of flood hazard risk evaluation. Journal of Hydraulic Engineering, 2001, (07): 8-12 (in Chinese)

54. Lambert J H, Li D. Evaluating risk of extreme events for univariateloss functions. Journal of Water Resources Planning and Manage- ment, 1994, 120(3): 382-399

55. Huang M C, Xie J C, Ruan B Q, Wang Y M. Model for assessing water shortage risk based on support vector machine. Journal of Hydraulic Engineering, 2007, (03): 255-259 (in Chinese)

56. Luo J G, Xie J C, Ruan B Q. Fuzzy comprehensive assessment model for water shortage risk based on entropy weight. Journal of Hydraulic Engineering, 2008, (09): 1092-1097 (in Chinese)

57. Gu W Q, Shao D G, Huang X F, Dai T. Multi-objective risk assessment on water resources optimal deployment. Journal of Hydraulic Engineering, 2008, (03): 339-345 (in Chinese)

58. Gu W Q, Shao D G, Jiang Y F. Risk Evaluation of Water Shortage in Source Area of Middle Route Project for South-to-North Water Transfer in China. Water Resources Management, 2012, 26(12): 3479-3493

59. Ashofteh P S, Haddad O B, Marino M A. Risk analysis of water demand for agricultural crops under climate change. Journal of Hydrologic Engineering, 2015. DOI: 10.1061/(ASCE)HE.19435584.0001053 (first published online)

60. Donald M, Cook A, Mengersen K. Bayesian network for risk of diarrhea associated with the use of recycled water. Risk Analysis, 2009, 29(12): 1672-1685

61. Qian L X, Wang H R, Zhang K N. Evaluation criteria and model for risk between water supply and water demand and its application in Beijing. Water Resources Management, 2014, 28(13): 4433-4447

62. Koutsoyiannis D. Uncertainty, entropy, scaling and hydrological stochastics. 1. Marginal distributional properties of hydrological processes and state scaling. Hydrological Sciences Journal, 2005, 50(3): 381-404

63. Koutsoyiannis D. Uncertainty, entropy, scaling and hydrological stochastics. 2. Time dependence of hydrological processes and time scaling. Hydrological Sciences Journal, 2005, 50(3): 405-426

64. Coles S, Tawn J. Seasonal effects of extreme surges. Stochastic Environmental Research and Risk Assessment, 2005, 19(6): 417427

65. Marshall L, Nott D, Sharma A. A comparative study of Markov chain Monte Carlo methods for conceptual rainfall-runoff modeling. Water Resources Research, 2004, 40(2): W02501

66. Firat F K, Yucemen M S. Determination of reliabffity based new load and resistance factors for reinforced concrete structural members. Teknik Dergi, 2014, 25(3): 6805-6829

67. Wu S J, Lien $\mathrm{H} \mathrm{C}$, Chang $\mathrm{C} \mathrm{H}$. Modeling risk analysis for forecasting peak discharge during flooding prevention and warning operation. Stochastic Environmental Research and Risk Assessment, 2010, 24(8): 1175-1191

68. Cacuci D G, Ionescu-Bujor M. A comparative review of sensitivity and uncertainty analysis of large-scale systems- II: Statistical methods. Nuclear Science and Engineering, 2004, 147(3): 204-217

69. Helton J C, Davis F J. Latin hypercube sampling and the propagation of uncertainty in analyses of complex systems. Reliability Engineering \& System Safety, 2003, 81(1): 23-69

70. Jiang Y, Nan Z, Yang S. Risk assessment of water quality using Monte Carlo simulation and artificial neural network method. Journal of Environmental Management, 2013, 122: 130-136

71. Zhang X, Ma W, Chen L. New similarity of triangular fuzzy number and its application. The Scientific World Journal, 2014, 2014: 215047 
72. Patra K, Mondal S K. Fuzzy risk analysis using area and height based similarity measure on generalized trapezoidal fuzzy numbers and its application. Applied Soft Computing, 2015, 28: 276-284

73. Qin X S, Huang G H, Zeng G M, Chakma A, Huang Y F. An interval-parameter fuzzy nonlinear optimization model for stream water quality management under uncertainty. European Journal of Operational Research, 2007, 180(3): 1331-1357

74. Maqsood I, Huang G H, Yeomans J S. An interval-parameter fuzzy two-stage stochastic program for water resources management under uncertainty. European Journal of Operational Research, 2005, 167(1): 208-225

75. Karimi I, Huellermeier E. Risk assessment system of natural hazards: A new approach based on fuzzy probability. Fuzzy Sets and Systems, 2007, 158(9): 987-999

76. Khan U T, Valeo C, He J X. Non-linear fuzzy-set based uncertainty propagation for improved DO prediction using multiple-linear regression. Stochastic Environmental Research and Risk Assessment, 2013, 27(3): 599-616

77. Zhu Y, Li Y P, Huang G H, Guo L. Risk assessment of agricultural irrigation water under interval functions. Stochastic Environmental Research and Risk Assessment, 2013, 27(3): 693-704

78. Gu J J, Guo P, Huang G H, Shen N. Optimization of the industrial structure facing sustainable development in resource-based city subjected to water resources under uncertainty. Stochastic Environmental Research and Risk Assessment, 2013, 27(3): 659-673

79. Chen C, Huang G H, Li Y P, Zhou Y. A robust risk analysis method for water resources allocation under uncertainty. Stochastic Environmental Research and Risk Assessment, 2013, 27(3): 713723

80. García Nieto P J, Alonso Fernández J R, de Cos Juez F J, Sánchez Lasheras F, Díaz Muñiz C. Hybrid modelling based on support vector regression with genetic algorithms in forecasting the cyanotoxins presence in the Trasona reservoir (Northern Spain). Environmental Research, 2013, 122: 1-10

81. Merabtene T, Kawamura A, Jinno K, Olsson J. Risk assessment for optimal drought management of an integrated water resources system using a genetic algorithm. Hydrological Processes, 2002, 16 (11): 2189-2208 